\title{
Numerical and Experimental Investigation on Dynamic Behavior in Turning Process of Thin-walled Workpieces made of 42CrMo4 Steel Alloy
}

\section{Zied Sahraoui}

University of Tunis (UT), Engineering National High School of Tunis (ENSIT)

\section{Nawel Glaa}

University of Tunis (UT), Engineering National High School of Tunis (ENSIT)

Kamel MEHDI ( $\sim$ kamel.mehdi@ipeiem.utm.tn )

University of Tunis (UT), Engineering National High School of Tunis (ENSIT) https://orcid.org/00000003-0193-4334

\section{Research Article}

Keywords: Machining, Turning, Thin walled workpiece, Cutting forces, Displacements, Vibrations, 3D FEM, Numerical Simulation, Modeling

Posted Date: September 28th, 2021

DOl: https://doi.org/10.21203/rs.3.rs-922054/v1

License: (9) This work is licensed under a Creative Commons Attribution 4.0 International License. Read Full License 


\title{
Numerical and experimental investigation on dynamic behavior in turning process of thin-walled workpieces made of $42 \mathrm{CrMo} 4$ steel alloy
}

\author{
Zied Sahraoui ${ }^{1}$, Nawel Glaa ${ }^{1}$, Kamel Mehdi ${ }^{1,2, *}$ \\ ${ }^{1}$ University of Tunis (UT), Engineering National High School of Tunis (ENSIT), Mechanics, Production \\ and Energetic Laboratory 'LMPE', Tunis, Tunisia \\ ${ }^{2}$ University of Tunis EL Manar (UTM), Preparatory Institute for Engineering Studies El Manar \\ (IPEIEM), PB. 244, 2092 Tunis, Tunisia \\ *Corresponding Author: \\ kamel.mehdi@ipeiem.utm.tn \\ https://orcid.org/0000-0003-0193-4334
}

\begin{abstract}
Machining thin-walled parts is generally cumbersome due to their low structural rigidity. Thus, to better understand the dynamic behavior of thin-walled parts during machining, various engineers and researchers in the field of metal cutting employ the Finite Element Method (FEM) due to its ability to highlight the physics involved in chip formation and the range of force generated in the cutting zone.

The results of numerical simulations are evaluated using comparison with experimental data. In this paper, we study the effect of feed rate as well as the thickness of the wall part made of $42 \mathrm{CrMo} 4$ steel alloy on the cutting forces and workpiece displacements both experimentally and numerically during roughing and finishing turning process. The numerical study is based on the development of a threedimensional (3D) Finite Element Model (FEM) in Abaqus/Explicit frame. In the model, the workpiece material is governed by a behavior law of Johnson-Cook. The detachment of the chip is simulated by a ductile fracture law also of Johnson-Cook. Numerical and experimental results show that the cutting forces and the quality of the machined surface depend not only on the choice of cutting parameters but also on the dynamic behavior of thin-walled parts due to their low rigidity and low structural damping during of the machining operation. Indeed, cutting forces are proportional to the feed rate and inversely proportional to the thickness of the part. The largest displacements recorded on the part are mainly along
\end{abstract}


the direction of the tangential component of the cutting force. The flexibility of the part generates instability in the cutting process, but the frequencies of the vibrations are higher than the frequency of rotation of the part.

\section{Keywords}

Machining, Turning, Thin walled workpiece, Cutting forces, Displacements, Vibrations, 3D FEM, Numerical Simulation, Modeling.

\section{Introduction}

In the machining field by cutting tool, the cutting process investigations and its optimization are still very delicate and financially costly. This is mainly due to the complexity of the multi-physical phenomena governing the tool-matter interaction [1]. Thus, recourse to the use of mathematical modeling tools (analytical, numerical, etc.) for the prediction of cutting tool/matter behavior becomes essential [2-4]. These prediction tools are only relevant if they are rigorously constructed and fed with reliable experimental data reflecting the reality of this cutting process $[5,6]$. The models generally developed in the literature have as objective functions the cutting phenomena (vibrations, chatter, temperature, forces, wear, etc.) where the characteristics of the machined part are linked to its integrity and to its resistance to fatigue (roughness, residual stresses, topography, hardness, microstructure, etc.) [7-10]. The study of the dynamic behavior of machined parts necessarily requires consideration of the aforementioned phenomena. Thus, Mehdi et al. [11,12] proposed a dynamic cutting force model for turning process of a thin walled workpiece in which dynamic deformations are different from those of massive ones. Due to the diversity of thin walled workpieces in the manufacture industry, and in order to have a global model of the dynamic behavior of a variety workpieces, the study have been oriented to the characterization of dynamic behavior of thin walled tubular parts. The model takes into account the 
damping due to interference between the tool flank and the machined workpiece surface. The different tests carried out clearly show the effect of cutting damping on cutting forces and the stability of cuttingprocess. Lorong et al. [13] presented an experiment accompanied with full time domain simulations featuring strong chatter and bringing forward the impact of the damping on the instability onset. Gerasimenko et al. [14] presented an experimental investigation completed with a numerical model of a straight turning operation on a thin-walled structure (tube). There work reveals the instabilities of the quasi-steady cutting under variable conditions, due to the structure's mass and compliance variation. Recently, Sahraoui et al., $[15,16]$ presented an analysis of a turning process stability using an analytical model supported and validated with experimental tests results of roughing and finishing operations conducted on AU4G1 thin-walled tubular workpieces with different thickness values. They showed the important effects of the dynamic behavior of the thin walled workpieces on the stability criteria, which cannot be ignored in machining process planning and cutting parameters selection. They justified the influence of an additional structural damping on chatter suppression in a machining of thin walled workpieces.

On the other hand, the finite element simulation methods have been used more in research related to the study of cutting processes (turning, milling or drilling). Given the diversity of the results offered by these simulation methods as well as the low implementation costs compared to those relating to experimental studies, the researchers developed several simulation models in order to study the cutting parameters. These models are closely linked to the material properties of the machined parts as well as to the phenomena which accompany the tool and the workpiece interaction. Several results have been obtained, such as the prediction of chip formation and the study of its morphology [17,18]. Likewise, other models have been developed to predict cutting forces and heat transfers during machining [19-22] or the influence of these parameters on the morphology of the chip [23]. 
This paper deals with the dynamic behavior of thin walled workpieces made of steel alloy $42 \mathrm{CrMo} 4$ during roughing and finishing turning process. To better understand the different damage observed during turning of these workpieces, a numerical study, supported and validated with experimental tests results, is proposed. The numerical study is based on the development of a three-dimensional (3D) Finite Element Model (FEM) in Abaqus/Explicit frame in order to predict the cutting forces in radial, tangential and axial directions and the impact of the machining parameters as well as the thickness of the wall part on the cutting forces and workpiece vibrations. In the model, the workpiece material is governed by a behavior law of Johnson-Cook. The detachment of the chip is simulated by a ductile fracture law also of Johnson-Cook.

The rest of the paper is organized as follows. The developed finite element model is presented in the next section. The experimental procedure is exposed in section 3. Experimental and numerical results are discussed in section 4 . The paper is concluded with the main observations and potential future work.

\section{Numerical Process}

\subsection{Behavior law}

The major characteristic of the chip formation process is the presence of intense deformations with high rates of deformation. Thus our simulation model is developed on the explicit version of the Abaqus finite element analysis software which supports the resolution of dynamic non-linear problems with this kind of conditions. In this study, the workpieces are made of $42 \mathrm{CrMo} 4$ steel materials which are characterized, in the case of a traction load, by an elastic behavior, a plastic behavior and a phase of damage. During this last phase, the mechanical properties of the material deteriorate. Analyzes of experimental tests, made by researchers, have shown the formation of micro-cracks and micro-cavities which leads to rupture. Therefore, the study of cutting processes requires the characterization of the actual behavior of the material through laws that describe the behavior and damage of the material. 
The mechanical behavior at deformation of the machined workpiece can be described by a thermoviscoplastic model which takes into account high deformation rates, inelastic deformations and the effects linked to the variation in temperature. The behavioral law Johnsons Cook has been implemented for flow stress of the workpiece (Eq. 1). This law is based on the value of the equivalent plastic deformation of an element. The damage occurs when the damage parameter reaches the value 1.

$$
\bar{\sigma}=\left[A+B\left(\bar{\varepsilon}^{p l}\right)^{n}\right]\left[1+C \ln \left(\frac{\bar{d}^{p l}}{\bar{d}}\right)\right]\left(1-\theta^{m}\right)
$$

where $\bar{\sigma}$ is the equivalent plastic stress, $\bar{\varepsilon}^{p l}$ is the equivalent plastic strain, $\bar{g}^{\text {pl }}$ is the equivalent plastic strain rate, $\bar{d}$ is the reference equivalent plastic strain rate, $A$ is the limit of elasticity of the material, $B$ and $n$ are the coefficients related to the work hardening, $C$ is the sensitivity coefficient to deformation rate and $m$ is the temperature sensitivity coefficient.

The constants $A, B, n, C$ and $m$ are given in the table 1 . Their values are determined based on the flow stress data obtained from literature mechanical tests.

$\hat{\theta}^{m}$ is the temperature ratio given by Eq. 2.

$$
\hat{\theta}^{m}=\frac{T-T_{\text {room }}}{T_{m}-T_{\text {room }}}
$$

where $T$ is the workpiece temperature, $T_{\text {room }}$ is the room temperature and $T_{m}$ is the melting temperature. In our study, $\hat{\theta}^{m}$ is equal to one because only the mechanical behavior of the process has been considered in the model. 
Table 1. 42CrMo4 Material Parameters for Johnson-Cook model

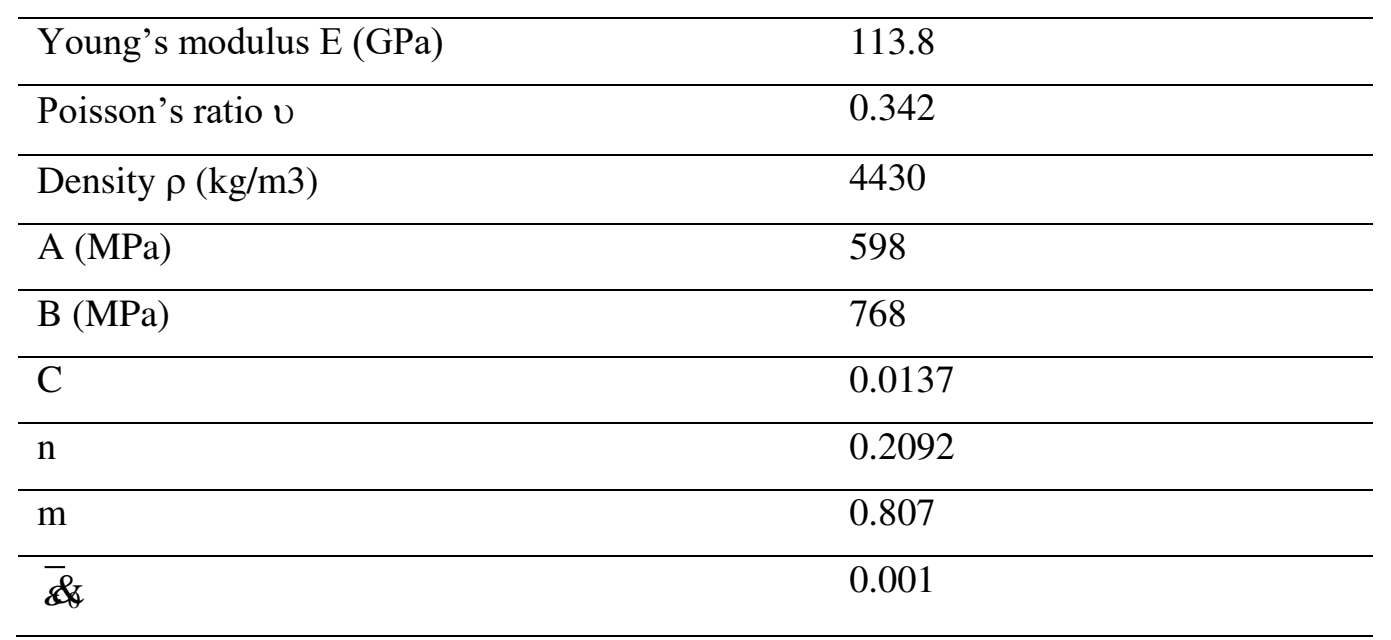

\subsection{Friction law}

The interactions between the chip and the cutting tool result in friction between two surfaces. With Abaqus, there is a "master" surface and a slave surface (geometry or mesh). The essential criterion in this contact is that the nodes relating to the slave surface do not penetrate into the "master" surface. In addition, normal vectors are calculated for each node. In the case of digital cutting simulations, the tool is defined as master and the workpiece is the slave.

The most used friction laws are that of Coulomb and that of Tresca. In the case of Coulomb's law, the two tangential and normal stresses exerted on the contact surfaces are linked by the following relation (Eq. 3) in the case of a rigid tool and the deformable part:

$$
\tau_{t} \leq \mu \sigma_{n}
$$

Where $\mu$ represents the friction coefficient.

The Tresca model imposes a constant friction threshold and the slip limit is independent of the normal stress. In this case, the friction law is given by Eq. 4:

$$
\tau_{t}<m \frac{\sigma_{e}}{\sqrt{3}}
$$


where $m c$ is the Tresca coefficient $(0 \leq m b \leq 1)$ and $\sigma_{e}$ is the elastic limit of the material of the workpiece.

In this simulation, the Coulomb model has been adopted with a friction coefficient value of 0.8 .

\subsection{Damage law}

The contact zone between cutting edge and machined part is characterized by significant plastic deformations where the laws of the mechanics of the media contained are not applicable. For a more realistic simulation, it is necessary to use a damage model. Figure 1 shows the result of the tensile test applied on metallic materials. In the damage phase, the stress tensor can be translated by the following relation describing the law of elasticity:

$$
\bar{\sigma}=(1-\bar{D}) \& \%=(1-\bar{D}) E\left(\varepsilon-\varepsilon_{p}\right)
$$

Where $\& /$ represents the tensor of effective stress, $E^{k}$ represents the tensor of elasticity, $\varepsilon$ is the total strain and $\varepsilon_{p}$ the viscoplastic strain. The term $\bar{D}$ represents the damage variable which can vary according to a linear or exponential law.

Damage initiation

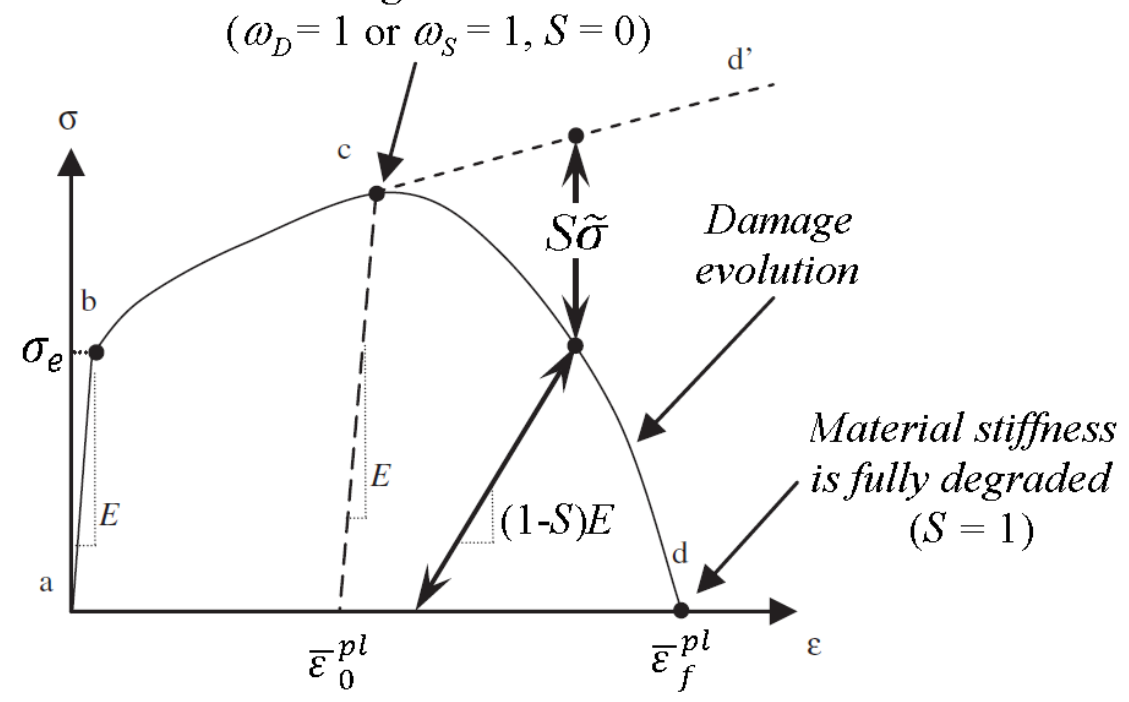

Figure 1. Tensile curve of a ductile metal [8]. 
The damage process is described by three phases: initiation of the damage at a deformation level, an evolution of the damage accompanied by increased loading and rupture. The initiation phase of the damage can be characterized by the following relationship (Eq. 6):

$$
\bar{\omega}=\sum\left(\frac{\Delta \bar{\varepsilon}_{p}}{\bar{\varepsilon}_{i}}\right)
$$

Where $\Delta \bar{\varepsilon}_{p}$ is the increment of the equivalent plastic deformation and $\bar{\varepsilon}_{i}$ is the deformation equivalent to the rupture of the material. The damage is initiated if $\bar{\omega}$ takes the value 1 . This term is calculated at each increment and for each mesh element.

A linear evolution of the damage is described by the following expression (Eq. 7):

$$
D_{\text {lin }}=\frac{\bar{u}}{\bar{u}_{f}}=\frac{\bar{u}}{2\left(\frac{G_{f}}{\sigma_{y}}\right)}
$$

An exponential evolution of the damage is described by the following expression (Eq. 8):

$$
D_{\exp }=1-\exp \left(-\int_{0}^{\bar{u}} \frac{\bar{\sigma}}{G_{f}} d u\right)
$$

Where $\bar{u}$ represents the equivalent plastic displacement, $\bar{u}_{f}$ is the fracture displacement, $\sigma_{y}$ is the flow stress and $G_{f}$ is the rate of energy restitution of the material.

$$
\left(G_{f}\right)_{i}=\left(\frac{1-v^{2}}{E}\right)\left(K_{C, i}\right)^{2} \text { with } i=I, I I
$$

Where $v$ is the Poisson coefficient of the material, E is its Young's modulus and $K_{C, i}$ is the factor describing the breaking strength (in mode $I$ (crack) or II (shear)) [23]. 
The models of damage are varied and they essentially describe the plastic deformation equivalent to rupture. These models are generally based on constants relating to each type of material which can be identified from experimental tests or numerical simulations. In our simulation, we have chosen to use the ductile damage and the shear damage criteria which describe the equivalent deformation of the material at break. The shear criterion is suitable for breaks due to the location of the shear band. The model supposes that the plastic strain equivalent at the beginning of the damage is function of the report of shear stress and the speed of deformation. The ductile criterion of the rupture is suitable for the ruptures due to the growth and the propagation of the cracks. The model supposes that the plastic strain equivalent at the beginning of the damage is function of the three axial of the stresses and the rate of strain.

\subsection{Modeling of cutting process}

The finite element simulation is based on the mesh of the regions studied into elements. The distribution, the density of the mesh and the dimensions of the elements are specified according to the problem studied. In the case of the cutting process, the mesh can never maintain its initial state. Changes are always present and the mesh risks the problem of distortion which leads to errors and to stopping of the calculation. The choice of the type of the elements, the automatic correction of the mesh (adaptive mesh) and the increase in the density of the localized mesh (dimensions of the elements) are presented as techniques which help to eliminate this problem. The simulation is developed via Abaqus/Explicit. The "Dynamic Explicit" module which supports nonlinear effects and large deformations has been exploited. The thermal effects are not taken into account within the framework of this simulation. In fact, we are mainly interested in studying the cutting forces as a function of the wokpieces wall thickness and the variation of the feed. 


\subsubsection{Modeling of cutting system}

In the simulation model, we have opted for a cantilever mounting system (Fig. 2). This choice is justified by the fact that the length to outside diameter ratio of the workpiece is less than 2 . The three jaws are modeled as a rigid body with a reference point which controls the imposed boundary conditions. The elements of mesh chosen are specific to the rigid type and they are also of triangular type R3D3 (linear) for Explicit resolution. The density of the mesh at the level of the surface in contact with the part respects that adopted for the part. Table 2 gives the considered cutting parameters for marching $42 \mathrm{CrMo} 4$ steel parts considered in numerical and experimental tests. The boundary conditions are imposed on the tool and the three jaws through their reference points. The tool has a constant feed rate along the $\mathrm{z}$ axis. The jaws turn at a constant angular speed around the feed rate axis. The rotational movement is transmitted to the workpiece through the jaws contact surface. For the contact properties, the part is considered as "slave", the jaws and the cutting tool are considered as "master". The type of contact chosen is general "General contact" with two types of properties: The tool and workpiece contact is with friction translated by the introduction of a coefficient of friction $\mu$. The jaws and workpiece contact is non-slip to transmit the rotational movement of the jaws towards the workpiece.

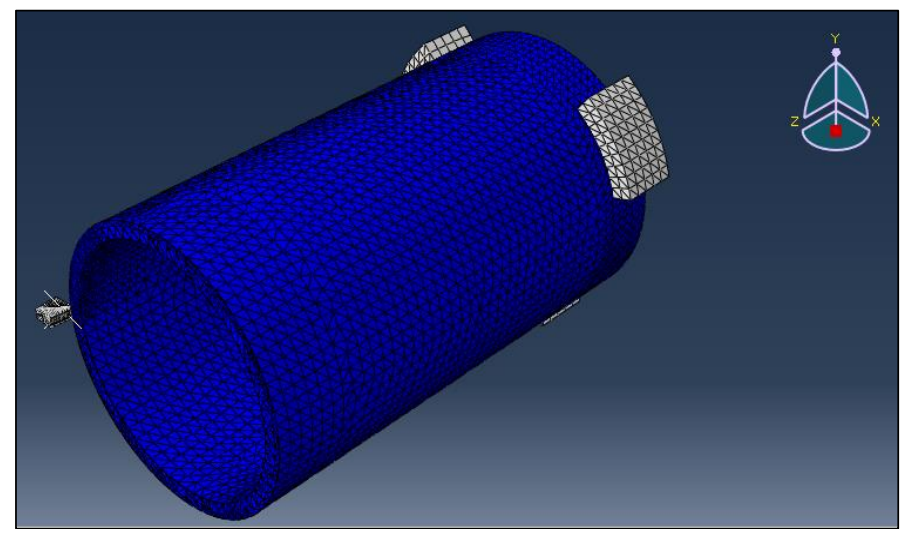

Figure 2. Model of cutting system 
Table 2. Considered input parameters in numerical and experimental tests for 42CrMo4 steel alloy

\begin{tabular}{|c|c|c|c|c|c|c|c|c|c|c|c|c|}
\hline \multirow[b]{3}{*}{ Test Ref. } & \multicolumn{12}{|c|}{ Machining operation } \\
\hline & \multicolumn{9}{|c|}{ Roughing } & \multicolumn{3}{|c|}{ Finishing } \\
\hline & R-1 & R-2 & R-3 & R-4 & R-5 & R-6 & R-7 & $\mathbf{R - 8}$ & R-9 & F-1 & F-2 & F-3 \\
\hline Wall thickness ep (mm) & 6 & 6 & 6 & 4.5 & 4.5 & 4.5 & 3 & 3 & 3 & 1.5 & 1.5 & 1.5 \\
\hline Depth of cut $a_{p}(\mathrm{~mm})$ & 1.5 & 1.5 & 1.5 & 1.5 & 1.5 & 1.5 & 1.5 & 1.5 & 1.5 & 0.5 & 0.5 & 0.5 \\
\hline Feed rate $f(\mathrm{~mm} / \mathrm{rev})$ & 0.2 & 0.3 & 0.4 & 0.2 & 0.3 & 0.4 & 0.2 & 0.3 & 0.4 & 0.1 & 0.125 & 0.16 \\
\hline Cutting speed $V c(\mathrm{~m} / \mathrm{min})$ & 160 & 160 & 160 & 160 & 160 & 160 & 160 & 160 & 160 & 200 & 200 & 200 \\
\hline
\end{tabular}

\subsubsection{Modeling of cutting tool}

The tool is considered in this simulation as a non-deformable (rigid) body. The chosen elements are specific to the rigid type (Discrete Rigid Element) and they are of quadratic type R3D4 (linear) for explicit resolution. The density of the mesh is important at the level of the cutting spout of the tool in order to respect the tool and workpiece contact. For this rigid body, we have associated a reference point which controls all possible movements. Numerical simulation concerns only the steel alloy $42 \mathrm{CrMo} 4$ governed by the law of Johnson-Cook, the details of the geometry of the tool are presented in the table 3. Tool references are CNMG 120408 and CNMG 120404 respectively for roughing and finishing operations.

With Abaqus the components, which are considered as a rigid body, are transformed into a rigid shell whose mesh is possible. The selected elements are specific to the rigid type (Discrete Rigid Element) and they are of quadratic type R3D4 (linear) for Explicit resolution. The mesh density is important at the nose of the tool in order to respect the tool / part contact as much as possible. For this rigid body, one associated a point of reference which controls all the possible movements (Fig. 3). 
Table 3. Geometric characteristics of cutting tools (roughing and finishing of 42CrMo4 steel parts).

\section{Parameters}

Tools noise radius: $R(\mathrm{~mm})$

Acuity radius of the cutting edge: $r(\mathrm{~mm})$

rake angle: $\gamma\left(^{\circ}\right)$

clearance angle: $\alpha\left(^{\circ}\right)$

Cutting edge angle: $\chi_{r}\left(^{\circ}\right)$

Complementary angle of the cutting edge direction: $\psi_{r}\left(^{\circ}\right)$

\section{Machining operation}

Roughing

0.8

0.4

0.04

0.03

7

2

6

6

95

95

$-5 \quad-5$

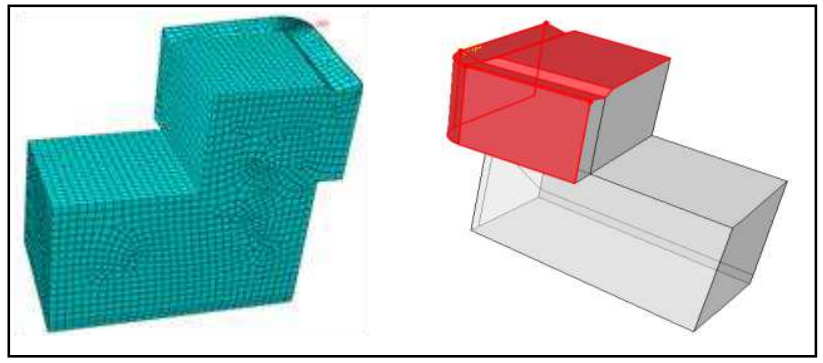

Figure 3. Cutting tool model (roughing operation)

\subsubsection{Modeling of machined parts}

The CAD models of the machined parts were developed with Abaqus software. The parts are thin tubes with a length "L" equal to $200 \mathrm{~mm}$ and an internal diameter "D" equal to $100 \mathrm{~mm}$. The wall thicknesses " $e_{p} "$ depend on the machining operation. Thus, for a roughing operation, the chosen

thicknesses are 3, 4.5 and $6 \mathrm{~mm}$. For a finishing operation, the wall thickness is $1.5 \mathrm{~mm}$. The material properties taken into account in the simulation are shown in Table 2.

The workpieces are considered to be deformable and meshed with linear tetrahedral elements C3D4. The highest mesh density is located in the part-cutting tool contact zone. The distortion control is 
activated in order to reduce the mesh errors during the tool and workpiece contact caused by intense deformations. For this type of element the adaptive mesh (ALE) cannot be applied.

\section{Experimental procedure}

The experimental tests were conducted with roughing and finishing operation using tubular parts with $200 \mathrm{~mm}$ length of and an internal diameter of $100 \mathrm{~mm}$. The workpieces material is the steel alloy 42CrMo4 which is used in mechanics for parts of different sizes (shafts, racks, crankshafts, gears, etc.) due to its good mechanical characteristics. For the roughing operation, the wall part thicknesses " $e_{p} "$ are 3, 4.5 and $6 \mathrm{~mm}$. For a finishing operation, the wall thickness is $1.5 \mathrm{~mm}$. Table 2 and Table 3 give the cutting process parameters and the cutting tool parameters used during the roughing and finishing operations. In total we have twelve experimental tests: Nine tests for the roughing operation and three tests for the finishing operation). The experiments consist in measuring firstly the cutting force components $F_{x}, F_{y}, F_{z}$ respectively along radial, tangential and axial directions and secondly the tangential workpiece vibrations along the Y direction. The experimental setup is illustrated in Figure 4. The measurement of the cutting forces components along the three directions $\mathrm{X}, \mathrm{Y}$ and $\mathrm{Z}$ is conducted using tri axial force piezoelectric dynamometer which can measure the cutting forces components signals in three directions during active cutting process. The workpiece displacement along the Y direction is measured using a capacitive sensor without contact fixed at a distance of $0.5 \mathrm{~mm}$ to the free end of the workpiece. The engine lathe is equipped with a $20 \mathrm{~kW} \mathrm{DC}$ motor. The rotation speed is controlled by an electronic regulator. The signals received from the dynamometer and the sensor, are acquired by a data acquisition system and analyzed using specific software installed on a laptop. 


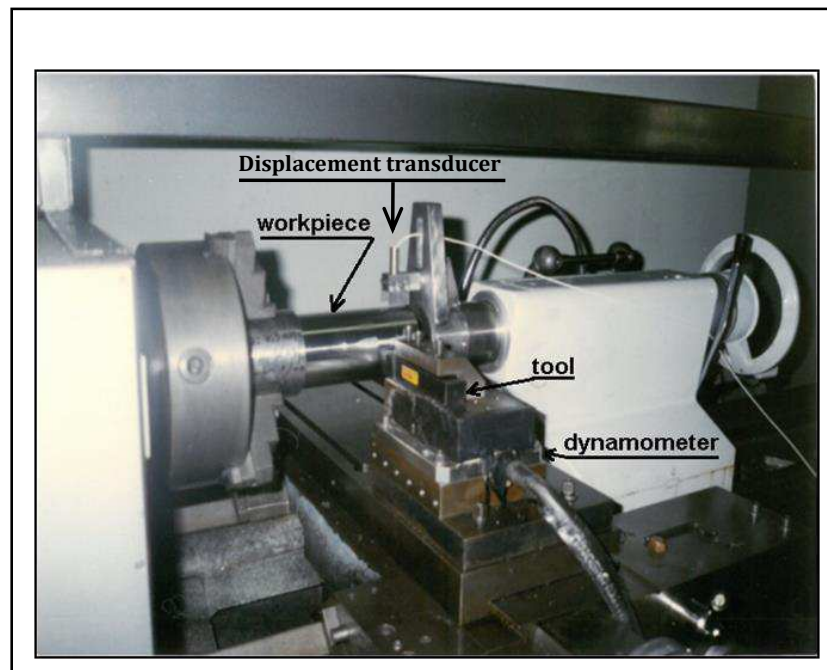

(a) Detail of the turning machine

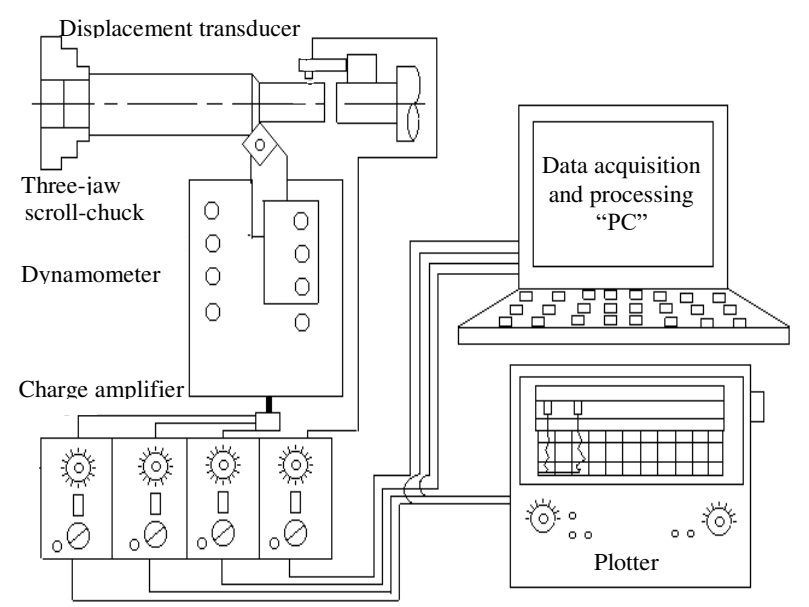

(b) Data acquisition and processing chain

Figure 4. Experimental device

\section{Results and discussions}

\subsection{Analysis of cutting force and radial vibration of the workpiece wall}

The experimental results of the twelve performed tests (Table 2) are summarized in Table 5. These experimental results show that:

- The average values of the cutting forces and of the radial displacement of the workpiece wall are proportional to the chip cross-section $\left(a_{p} \times f \mathrm{~mm}^{2}\right)$. These average values are slightly influenced by the wall thickness of the machined parts. For the finishing tests (small chip cross-section) the average values are lower than those for the roughing tests (large chip crosssection). Indeed, an increase of the feed rate $f$ from $0.2 \mathrm{~mm} / \mathrm{rev}$ to $0.4 \mathrm{~mm} / \mathrm{rev}$ is accompanied by a significant increase in the average values of $F_{x}, F_{y}$ and $F_{z_{-}}$: for the workpiece of $3 \mathrm{~mm}$ thick, $F_{x}, F_{y}$ and $F_{z}$ increase by $102 \%, 80 \%$ and $79 \%$ respectively. For the workpiece of 4.5 mm thick, the increase of $F_{x}, F_{y}$ and $F_{z}$ is respectively $104 \%, 78 \%$ and $75 \%$. Finally, for the workpiece of $6 \mathrm{~mm}$ thick, $F_{x}, F_{y}$ and $F_{z}$ increase by $102 \%, 79 \%$ and $78 \%$ respectively. 
- The variation of the radial, tangential and axial components $F_{x}, F_{y}$ and $F_{z}$ of the cutting force as well as the radial displacement of the workpiece wall around their average value is low for the roughing tests where the wall thickness $e_{p} \geq 3.5 \mathrm{~mm}$. However, this variation intensifies for the finishing tests where the wall thickness $e_{p}=1.5 \mathrm{~mm}$. These variations have a significant effect on the quality of the surface finish of the workpiece wall.

- For the roughing operations, no vibrated surfaces were observed except for test "R-9". In this case, the flexibility of the workpiece limits the chip cross-section value without vibrations. For the other tests, variations of the dynamic cutting forces were measured. The variations are situated from $\pm 10 \%$ to $\pm 23 \%$ of the average value.

From these results we can conclude that the cutting forces and the quality of the machined surface depend not only on the choice of cutting parameters but also on the dynamic behavior of thin-walled parts due to their low rigidity and low structural damping during of the machining operation. Figure 5 shows the variation of tangential cutting force and of the radial displacement of the wall of the part respectively for the roughing test "R-3" (Fig. 5-a) and for the finishing test "F-2" (Fig. 5-b). In roughing, the cutting process is accompanied by low amplitude vibrations while in finishing the vibrations are intense.

Table 4. Average values of experimental cutting forces and radial displacements of workpiece wall

\begin{tabular}{lllllll}
\hline Test Ref. & $f(\mathrm{~mm})$ & $F_{x}(\mathrm{~N})$ & $F_{y}(\mathrm{~N})$ & $F_{z}(N)$ & $\operatorname{dep}(\mu \mathrm{m})$ & Observed surface \\
\hline R-1 & 0.2 & 256 & 787 & 393 & -61 & N. V. \\
R-2 & 0.3 & 367 & 1074 & 513 & -95 & N. V. \\
R-3 & 0.4 & 519 & 1417 & 707 & -132 & N. V. \\
R-4 & 0.2 & 250 & 778 & 383 & -63 & N. V.
\end{tabular}




\begin{tabular}{lllllll} 
R-5 & 0.3 & 357 & 1042 & 489 & -81 & N. V. \\
R-6 & 0.4 & 511 & 1391 & 671 & -119 & N. V. \\
R-7 & 0.2 & 260 & 795 & 400 & -69 & N. V. \\
R-8 & 0.3 & 373 & 1088 & 522 & -119 & N. V \\
R-9 & 0.4 & 527 & 1430 & 713 & -135 & L. V. \\
F-1 & 0.1 & 90 & 249 & 140 & -39 & V. \\
F-2 & 0.125 & 98 & 190 & 99 & -34 & V. \\
F-3 & 0.16 & 156 & 307 & 167 & -49 & V. \\
\hline
\end{tabular}

N. V. = No Vibrations; L. V. = Light Vibrations, V. = Vibrations
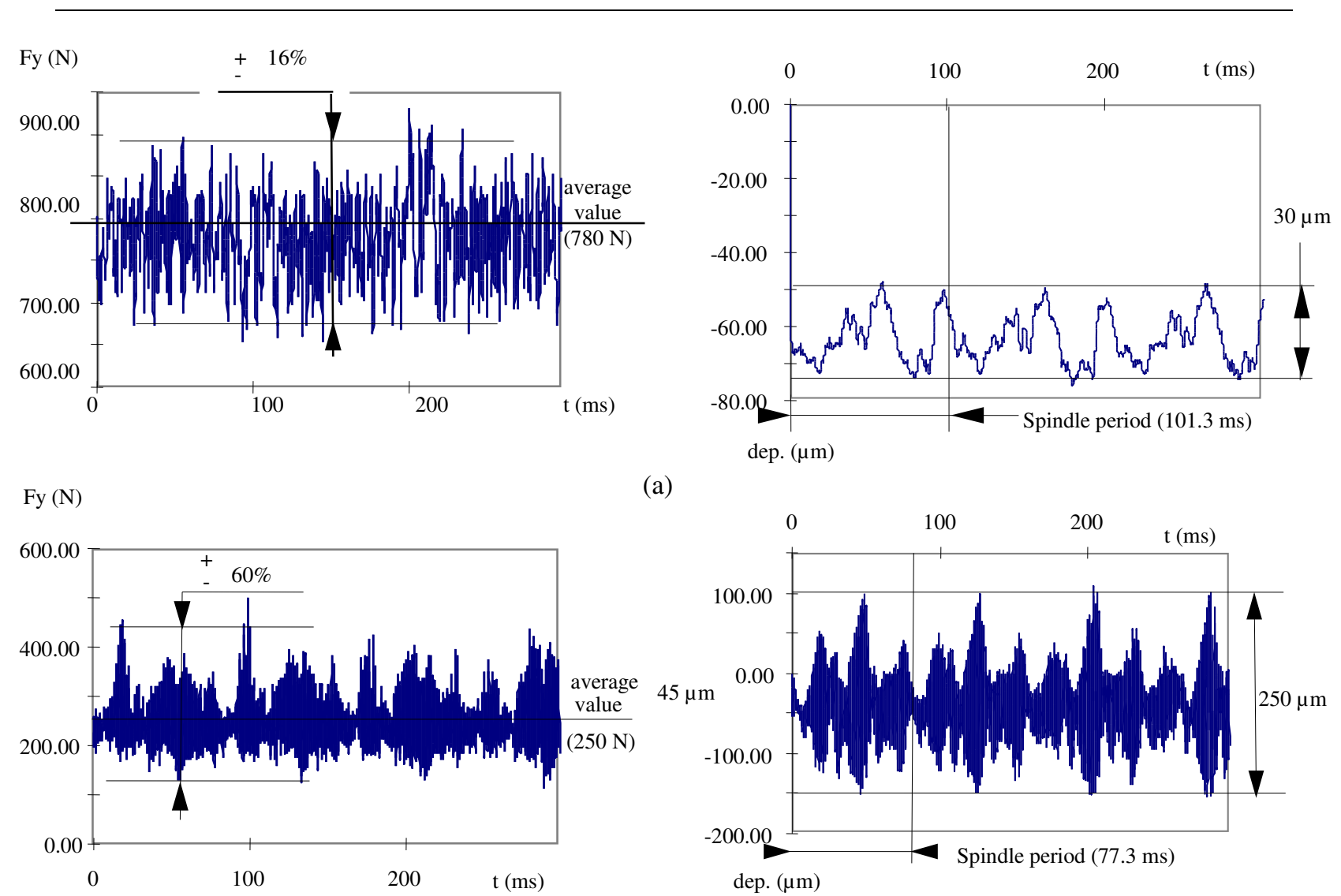

(a)

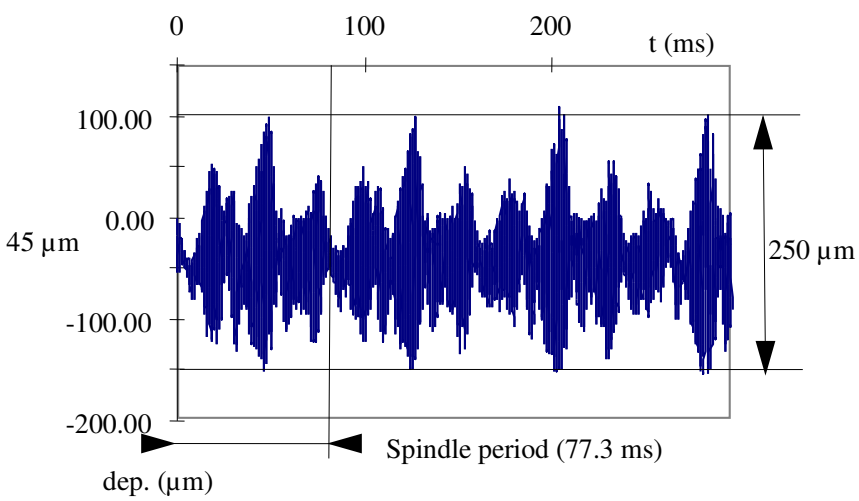

(b)

Figure 5. Tangential cutting force and radial displacement of the workpiece wall during machining: (a) - Roughing test "R-4"; (b) - Finishing test "F-2" 
Figure 6 illustrates a comparison between the values of the radial, tangential and axial cutting forces $F_{x}, F_{y}$ and $F_{z}$ obtained experimentally and by simulation, based on the feed rate during the roughing and finishing operations. The experimental values of $F_{x}, F_{y}$ and $F_{z}$ are denoted respectively $F_{x_{-}} \exp , F_{y_{-} \exp }$ and $F_{z \_ \text {exp. }}$ Those obtained using the analytical model, presented in [16], are denoted respectively $F_{x_{-} s i m}$, $F_{y_{\_} \text {sim }}$ and $F_{z_{-} \text {sim. }}$. Finally, those, obtained using the FEM, are denoted respectively $F_{x_{-} f e m}, F_{y_{-} f e m}$ and $F_{z_{-} f e m}$. In the case of roughing operations (Fig. 6 a-c), the values of the experimental tests and those obtained by the analytical model show agreement in the results of the three components of the total cutting force. Acceptable error values are recorded which do not exceed $15 \%$ in the case of the axial component $F_{z}$ relating to test referred R-2.

During finishing operations (Fig. 6-d), we note that there is agreement between the cutting forces measured experimentally and those simulated analytically. In the case of test F-2, a difference of $18 \%$ is recorded between the axial force measured experimentally and that simulated analytically. However, we can notice that the average values of the radial, tangential and axial cutting forces simulated using the FEM are lower than those measured experimentally.

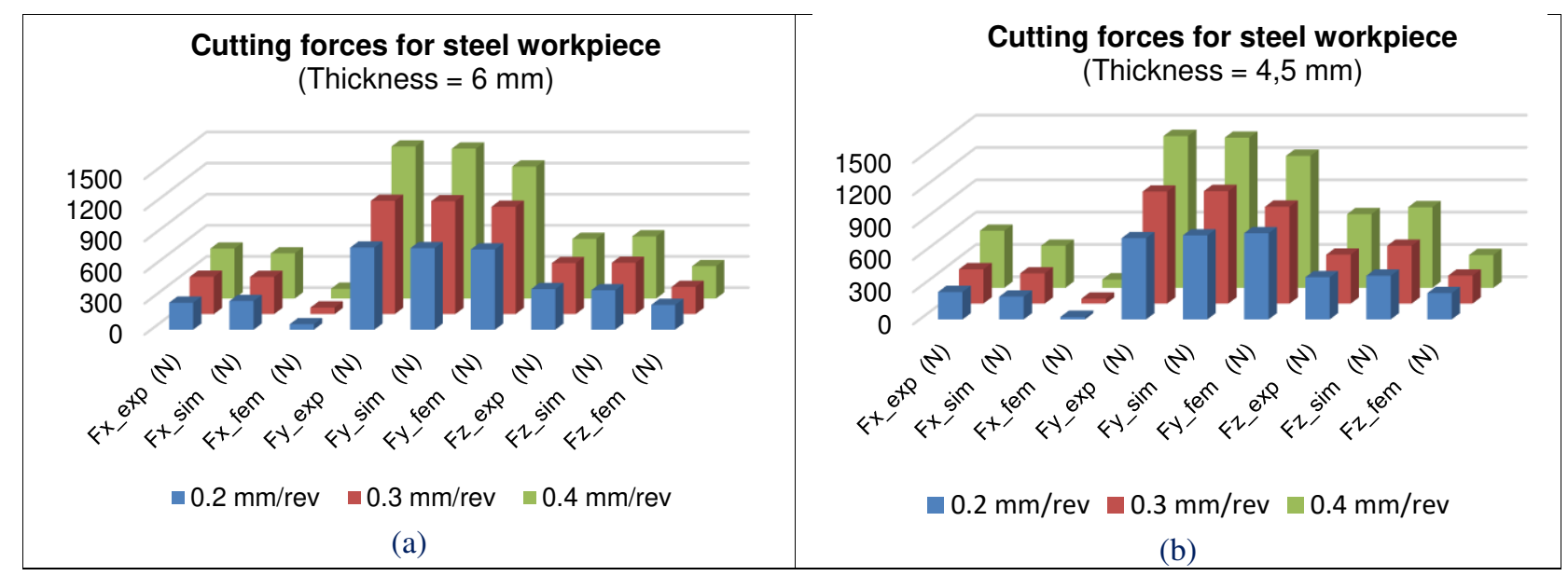




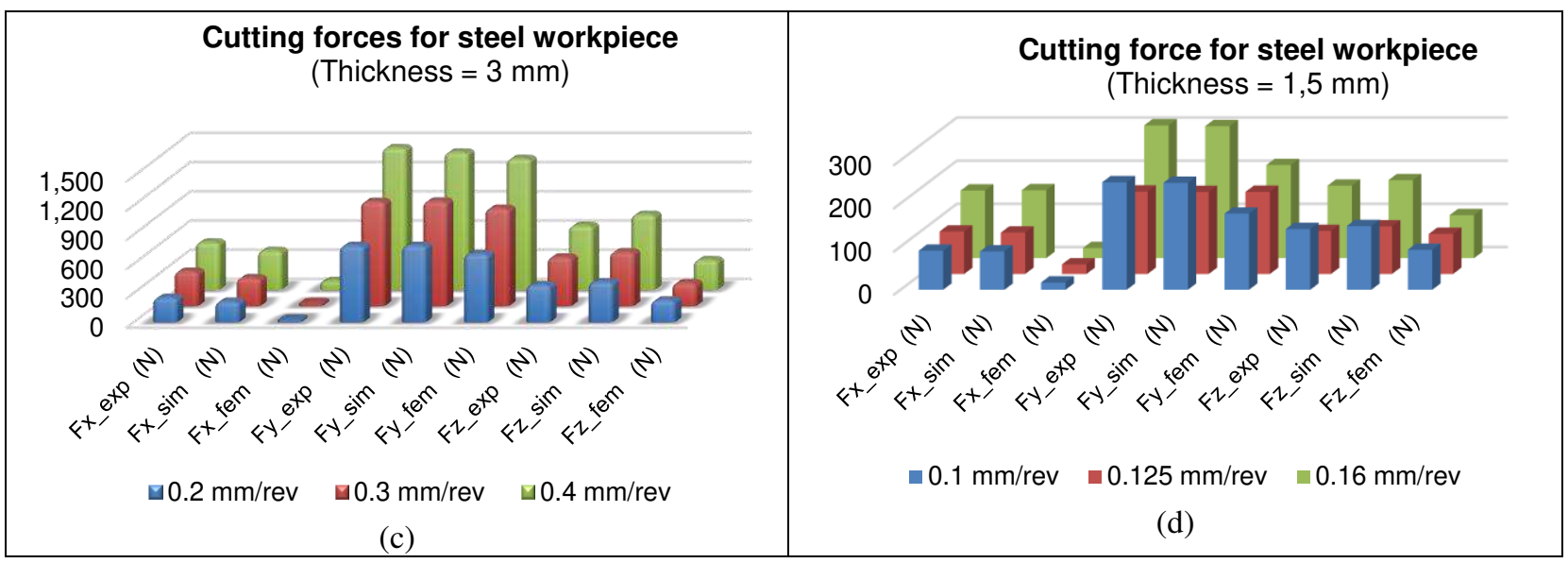

Figure 6. Radial, tangential and axial cutting forces during roughing and finishing operations:

(a) Tests R-1, R2 et R3, (b) Tests R-4, R-5 et R-6, (c) Tests R-7, R-8 and R-9, (d) Tests F-1, F-2 et F-3

The FEM was used to predict the workpiece wall displacements $U_{x}, U_{y}, U_{z}$ respectively along radial, tangential and axial directions at the free end of the workpiece. The workpiece wall vibrations can be simulated by imposing a coupling constraint between a reference point (RP-1) located on the axis of revolution and the circumferential internal surface of the free end of the workpiece (Fig. 7).

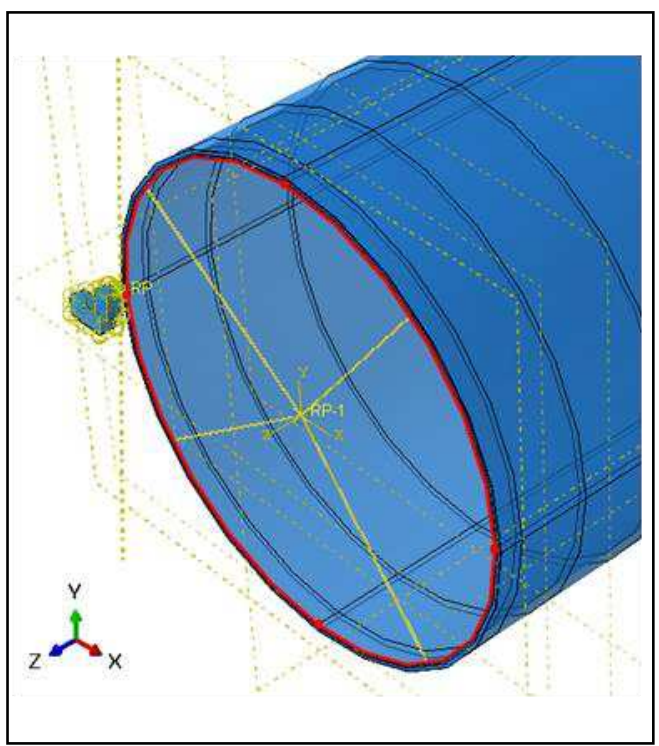

Figure 7. Point de référence (RP-1) et surface (en rouge) associée pour la mesure des vibrations des pièces.

Figures 8 shows the displacements of the reference point of workpieces with $6 \mathrm{~mm}, 4.5 \mathrm{~mm}$ and 1.5 mm thicknesses during numerical roughing operations R-2, R-3, R-5 and R-6 and finishing operations F- 
2 and F-3. We evoke these results to emphasize the nature of the vibrations during the section without however validating these results experimentally because each model has its own specificity of measurement point or calculation of vibrations. According to this figure, the largest displacements in roughing and finishing operations are recorded in the tangential direction $\left(U_{y}\right)$ followed by the radial direction $\left(U_{x}\right)$. Indeed, the part is more flexible in these two directions, which explains the low vibrations in the axial direction $\left(U_{z}\right)$. We can note that displacements for the finishing operations are superior to those for roughing operations with amplitudes of $0.1 \mathrm{~mm}$ along the tangential direction. Likewise, we notice the presence of a radial deformation at the free end of the part (shell mode). The deformation of the part during machining is illustrated by figure 9 relatively for roughing tests (R-2 and R-5 ) and finishing test (F-2). This deformation can justify the displacements of the reference point (RP1) located on the axis of revolution of the part. 


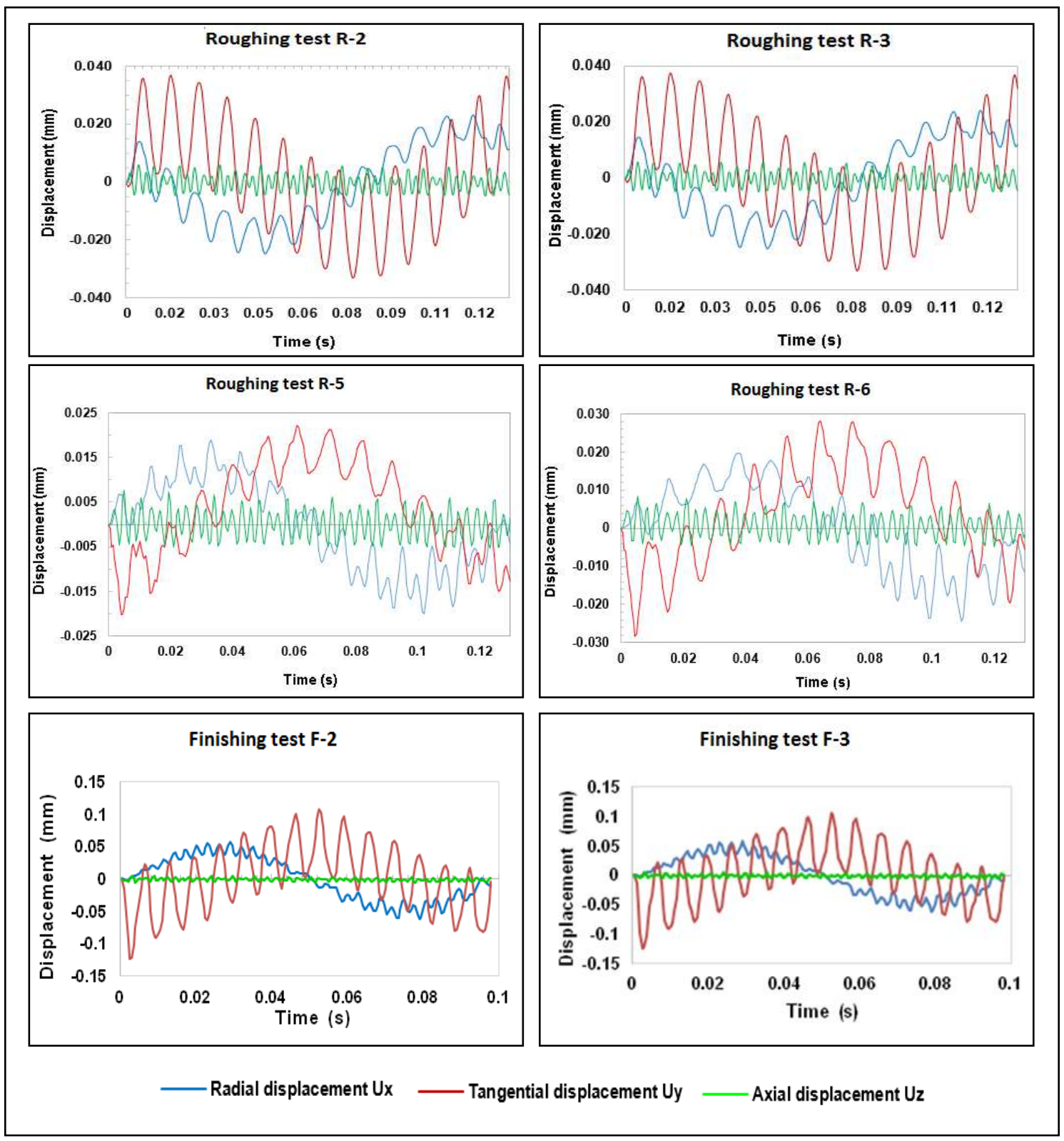

Figure 8.

Vibrations simulées au point de référence au cours les opérations d'ébauche R-2, R-3, R-5 et R-6 


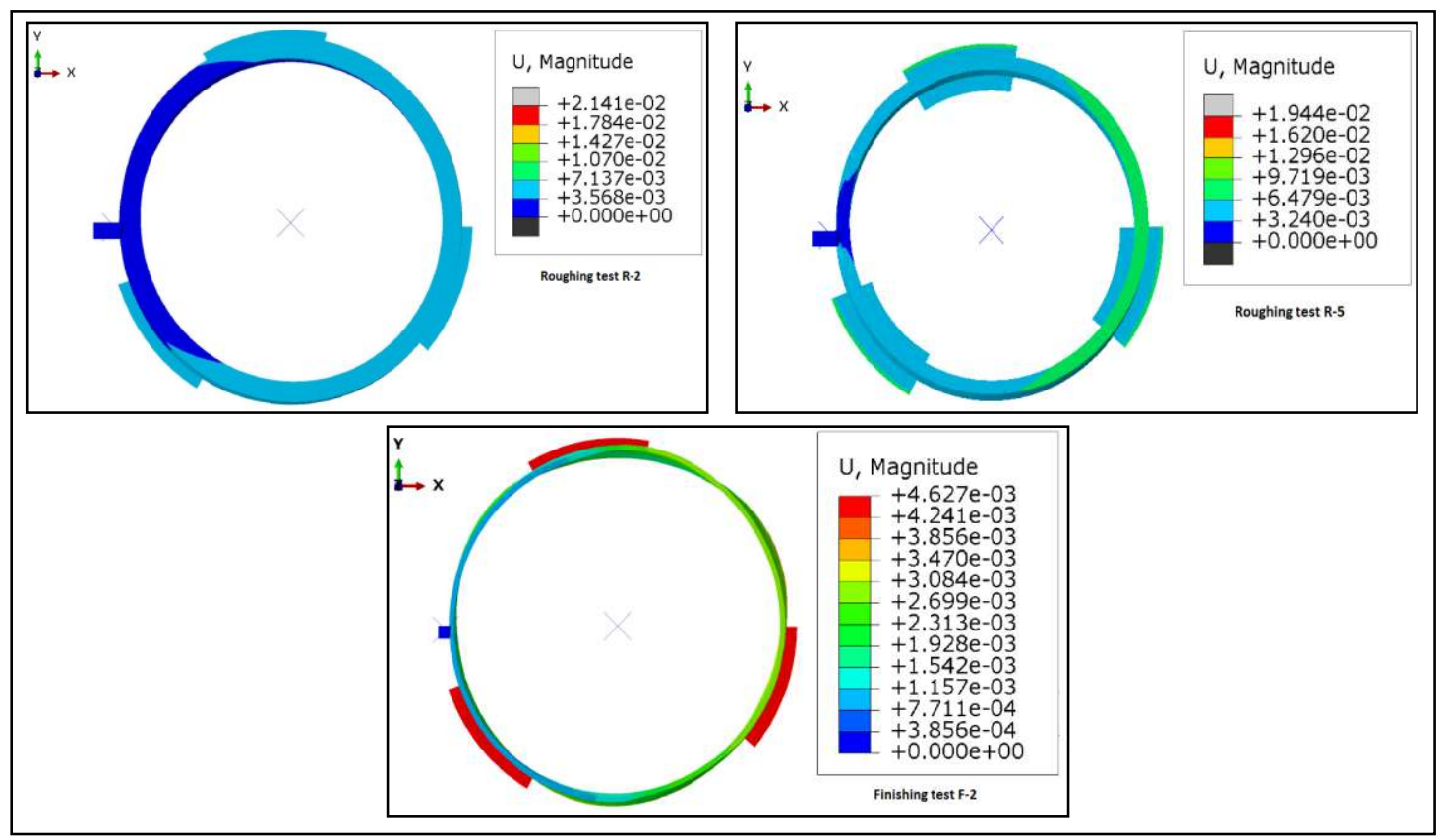

Figure 9.

Simulated of radial deformation at the free end of the workpiece for roughing tests R2 and R-5 and finishing test F-2

Using the analytical stability lobes model, described in [16], figure 10 shows comparison of the vibratory state of the roughing and finishing conducted tests with the stability lobes. For a workpiece with $6 \mathrm{~mm}$ thick, corresponding to roughing tests R-1, R-2 and R-3 (Fig. 10-a), it can be noted that for a depth of cut of $1.5 \mathrm{~mm}$ and for the two feeds per tooth 0.2 and $0.3 \mathrm{~mm} / \mathrm{rev}$, the cutting process is stable for a spindle speed of $625 \mathrm{rpm}$. For the three values of the feed rate $0.2,0.3$ and $0.4 \mathrm{~mm} / \mathrm{rev}$, a zone of stability is located for a depth of cut equal to $1.3 \mathrm{~mm}$ and a spindle speed equal to $630 \mathrm{rpm}$. It is noted that for the roughing experimental tests, the values retained for the spindle speed $(450.7 \mathrm{rpm})$ and the depth of cut $(1.5 \mathrm{~mm})$ are located in unstable zones.

In the case of the roughing operation of workpiece with $4.5 \mathrm{~mm}$ thick (Fig. 10-b) corresponding to the three roughing tests R-4, R-5 and R-6, the cutting depth allowing a stable zone is limited to $1.4 \mathrm{~mm}$ with a spindle speed of $500 \mathrm{rpm}$ and a feed rate equal to $0.2 \mathrm{~mm} / \mathrm{rev}$. The choice of a cutting depth equal to $1 \mathrm{~mm}$ is possible for the two feeds per revolution 0.2 and $0.3 \mathrm{~mm} / \mathrm{rev}$ and a spindle speed of $500 \mathrm{rpm}$. 
For the three values of the feed rate $0.2,0.3$ and $0.4 \mathrm{~mm} / \mathrm{rev}$, a depth of cut equal to $0.8 \mathrm{~mm}$ is located in the stable zone with a spindle speed equal to $500 \mathrm{rpm}$.

In the case of the roughing operation of workpiece with $3 \mathrm{~mm}$ thick (Fig. 10-c) corresponding to the three roughing tests R-7, R-8 and R-9, in order to migrate to the stable zones, it is necessary to increase the spindle speed and reduce the depth of cut. To maintain low spindle speeds, the depth of cut should be less than $1 \mathrm{~mm}$. This value is reached for the feed $0.2 \mathrm{~mm} / \mathrm{rev}$ and a spindle speed between 410 and $415 \mathrm{rpm}$.

In the case of the finishing operation of workpiece with $1.5 \mathrm{~mm}$ thick (Fig. 10-d) corresponding to the three finishing tests F-1, F-2 and F-3, in order to migrate to stable zones, it is necessary to increase the spindle speed and decrease the depth of cut. For a depth of cut equal to $0.5 \mathrm{~mm}$, the stable zones are located for a spindle speed greater than $1000 \mathrm{rpm}$.

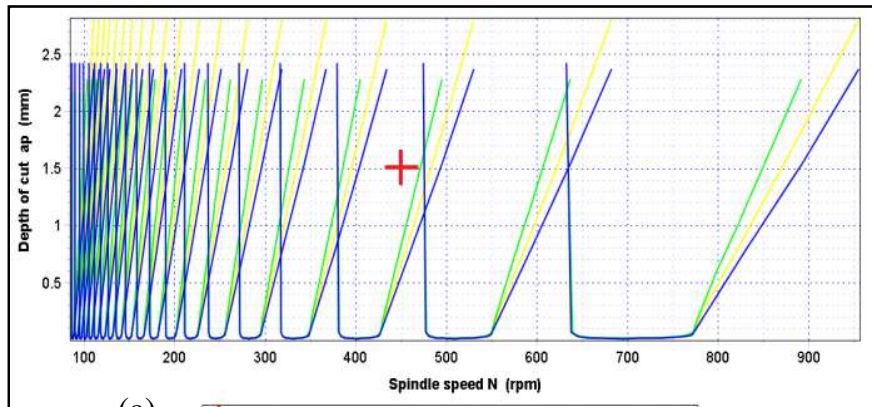

(a)

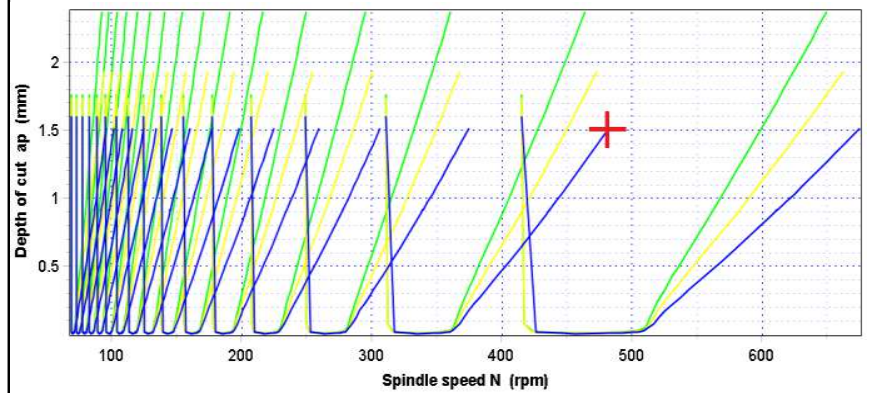

(c) \#Experimental parameters $-0.2 \mathrm{~mm} / \mathrm{rev}-0.3 \mathrm{~mm} / \mathrm{rev}-0.4 \mathrm{~mm} / \mathrm{rev}$

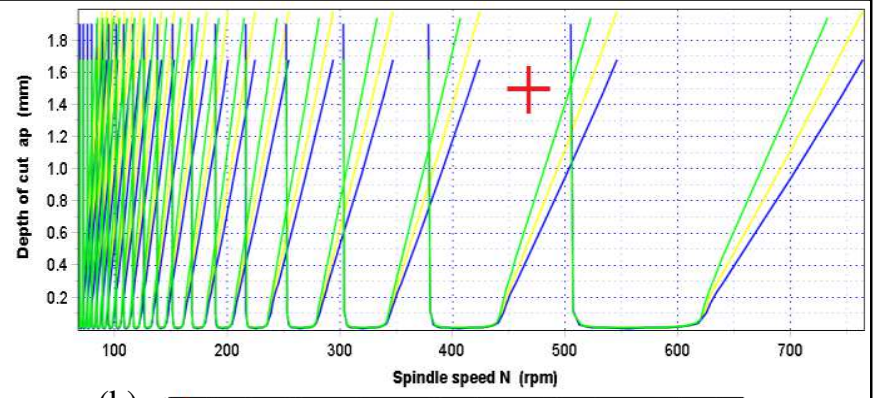

(b) + Experimental parameters $-0.2 \mathrm{~mm} / \mathrm{rev}-0.3 \mathrm{~mm} / \mathrm{rev}-0.4 \mathrm{~mm} / \mathrm{rev}$

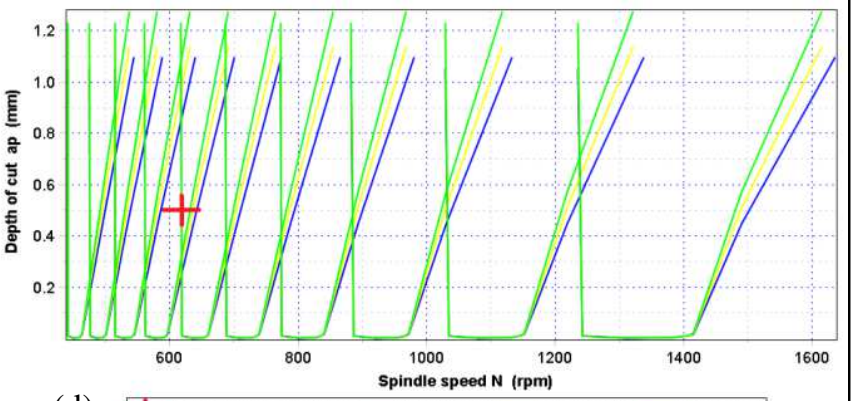

(d)

Figure 10. Comparison of the vibratory state of the roughing and finishing tests with the stability lobes: (a) Tests R-1, R2 et R3, (b) Tests R-4, R-5 et R-6, (c) Tests R-7, R-8 and R-9, (d) Tests F-1, F-2 et F-3 
Figure 11 represents the FFT spectra of the experimental radial vibrations $\left(U_{y}\right)$ of the workpiece wall during roughing and finishing operations. In roughing operations, the wall of machined parts vibrates at low frequencies. Indeed, the peaks of the spectra are visible only at low frequencies and do not exceed $15 \mathrm{~Hz}$. Thus, for parts $6 \mathrm{~mm}$ thick (tests R-1, R-2 and R-9), the signals of vibrations consist of several harmonics which are multiples of the fundamental signal frequency $4.9 \mathrm{~Hz}$. The increase in the amplitude or modulus of the most intense peaks as a function of the feed rate is small: from 6.4 to $7.3 \mathrm{~Hz}$. We notice that the signals are made up of practically the same frequencies. Indeed, for a feed rate equal to $0.2 \mathrm{~mm} / \mathrm{rev}$ (test R-1), the frequencies are $9.8 \mathrm{~Hz}$ and $13.4 \mathrm{~Hz}$. For a feed rate of 0.3 $\mathrm{mm} / \mathrm{rev}$ (test R-2), these harmonics correspond at frequencies $4.9 \mathrm{~Hz}, 8.5 \mathrm{~Hz}$ and $13.4 \mathrm{~Hz}$. And finally, for a feed rate of $0.4 \mathrm{~mm} / \mathrm{rev}$, the frequencies are $4.9 \mathrm{~Hz}, 8.5 \mathrm{~Hz}$ and $13.4 \mathrm{~Hz}$. For these workpieces, the spindle frequency is $7.5 \mathrm{~Hz}(450.7 \mathrm{rpm})$. Thus for the first three roughing operations (tests R-1, R-2 and R-3), the wall of the workpiece vibrates at frequencies in the vicinity of its spindle frequency.

For the roughing operations of $4.5 \mathrm{~mm}$ thick parts (tests R-4, R-5 and R-6), we notice an evolution of the vibration frequency compared to that recorded with a $6 \mathrm{~mm}$ thick part. This frequency passes from $9.8 \mathrm{~Hz}$ for the roughing operation R-4 with a feed rate of $0.2 \mathrm{~mm} / \mathrm{rev}$ to $13.4 \mathrm{~Hz}$ for the roughing operation R-6 with a feed rate of $0.4 \mathrm{~mm} / \mathrm{rev}$. The increase in the feed rate is also accompanied by an amplification of the amplitude of the peaks of the spectra. We note an evolution from 8.6 for the R-4 roughing operation to 25.3 for the R-6 roughing operation. The amplitude of the peak describes the level of power contained in the signal. Thus its significant increase is equivalent to the amplification of the amplitudes of the time signal. This aligns with the experimental results (Table 4) and our interpretations described in the previous paragraph which indicate that an increase in the feed rate is accompanied by an amplification of the vibrations of the workpieces wall. The signals recorded for these workpieces are made up of several harmonics which are multiple of the fundamental signal frequency 4.9 Hz. For a feed rate of $0.2 \mathrm{~mm} / \mathrm{rev}$, the frequencies are $4.9 \mathrm{~Hz}, 9.8 \mathrm{~Hz}$ and $14.7 \mathrm{~Hz}$. For a feed rate of $0.3 \mathrm{~mm} / \mathrm{rev}$, these harmonics correspond to the frequencies $4.9 \mathrm{~Hz}, 9.8 \mathrm{~Hz}$ and $23.2 \mathrm{~Hz}$. And finally for a feed rate $0.4 \mathrm{~mm} / \mathrm{rev}$, frequencies correspond to $4.9 \mathrm{~Hz}$ and $13.4 \mathrm{~Hz}$. For the chosen cutting parameters, the workpiece vibrates at frequencies in the vicinity of the spindle frequency $7.8 \mathrm{~Hz}(467.3$ rpm).

For the roughing operations of workpieces of $3 \mathrm{~mm}$ thick (tests: R-7, R-8 and R-9), when the feed rate increases from $0.2 \mathrm{~mm} /$ rev to $0.4 \mathrm{~mm} / \mathrm{rev}$, the frequency of vibrations increases from $9.8 \mathrm{~Hz}$ 
to $13.4 \mathrm{~Hz}$. The spectrum vibration contains a single peak whose amplitude increases from 11.2 to 218.9. The spectrum corresponding to a feed rate $0.3 \mathrm{~mm} / \mathrm{rev}$ is made up of 3 harmonics $4.9 \mathrm{~Hz}, 9.8 \mathrm{~Hz}$ and $14.7 \mathrm{~Hz}$. These frequencies are also multiples of the fundamental signal frequency 4.9 Hz. For the chosen cutting parameters, the workpiece vibrates also at frequencies in the vicinity of the spindle frequency $8 \mathrm{~Hz}(480,468 \mathrm{rpm})$.

Regarding the finishing operations of $1.5 \mathrm{~mm}$ thick parts (tests F-1, F-2 and F-3), the spectra show a multitude of frequencies with very variable amplitudes. The amplitude peaks visible on the spectra are located at high frequencies compared to those recorded in the case of the roughing. Indeed, the spectrum is concentrated in the vicinity of the frequency $550 \mathrm{~Hz}$ which is considered high compared to the frequency of the spindle $10.3 \mathrm{~Hz}(618 \mathrm{rpm})$. Thus the finished workpiece vibrates at frequencies higher than that of its rotation. The recorded spectra are made up of several harmonics. For a feed rate of $0.1 \mathrm{~mm} / \mathrm{rev}$, the frequency of the most intense peak is $542 \mathrm{~Hz}$ accompanied by secondary peaks between $510 \mathrm{~Hz}$ and $567 \mathrm{~Hz}$. For a feed rate of $0.125 \mathrm{~mm} / \mathrm{rev}$, the frequency of the more intense peak is $533 \mathrm{~Hz}$ accompanied by secondary peaks between $507 \mathrm{~Hz}$ and $573 \mathrm{~Hz}$. For a feed rate of $0.160 \mathrm{~mm} / \mathrm{rev}$, the spectrum presents two peaks. The frequency of the most intense peak is $493.2 \mathrm{~Hz}$ and the frequency of the secondary peak is $513 \mathrm{~Hz}$. An increase in the feed rate is also accompanied by an amplification of the amplitude of the peaks. The amplitude of the most intense peaks ranges from 345.6 to 1235.4. So, when finishing even with a slight increase in feed rate, the energy stored in the signal amplifies considerably at high frequencies that dominate the temporal signals.

In summary, for roughing and finishing operations, the vibrations of the workpiece wall in the tangential direction at the free end are proportional to the feed rate. In fact, with the same cutting parameters, the highest vibration values are recorded for the steel thin workpiece wall. In roughing, the wall of the machined part vibrates at low frequencies which do not exceed $15 \mathrm{~Hz}$ in the vicinity of the spindle rotation frequency. While finishing, the vibration frequencies are high in the vicinity of $550 \mathrm{~Hz}$. In addition, the amplitude of the peaks which describes the level of power contained in the signals shows an increase similar to that of the amplitudes of the temporal signal. Indeed, the experimental results indicate that an increase in the feed rate is accompanied by a considerable amplification of the vibrations of the machined workpiece wall. Thus, the response of the cutting system depends on the choice of feed rate and the thickness of the workpiece wall. This result shows the importance of the choice of cutting parameters (low feed rate) and the rigidity of the worpiece on the stability of the cutting process. 


\subsection{Von Mises stress field distribution}

Figure 12 describes the Von Mises stress field distribution relating to the numerical roughing and finishing tests. From this figure, the most important stress values are recorded at the cutting edge contact of the tool and workpiece. This causes the progressive degradation of the properties of the material (rigidity) and therefore the elimination of the elements. The other areas of the part (which will form the future chip) are also subject to significant stresses, but they reach the maximum value only in the event of contact with the tool. However, our interest is focused on the prediction of cutting forces. Thus, we have chosen to reduce the value of the parameter of the maximum degradation of the elements of the mesh. As a result, the chip morphology is not observed in the simulation. According to these figures, we also distinguish the primary shear zones (at the level of the shear plane) where the material undergoes a permanent and secondary plastic deformation (at the level of the cutting surface) between the tool and the chip. Their distributions around the contact zone are variable due to variations in the contact surfaces in movements between the tool and the part.

From figure 12, it can be seen that, in roughing operation of parts with $3 \mathrm{~mm}$ thick, the stress increases when the feed rate increases. And for parts of 4.5 and $6 \mathrm{~mm}$ thickness, the stress is not too much influenced by the feed rate. For the finishing operation, the stresses reach their maximum values at the cutting edge contact of the tool and the workpiece. And we can also distinguish the primary and secondary shear zones. 

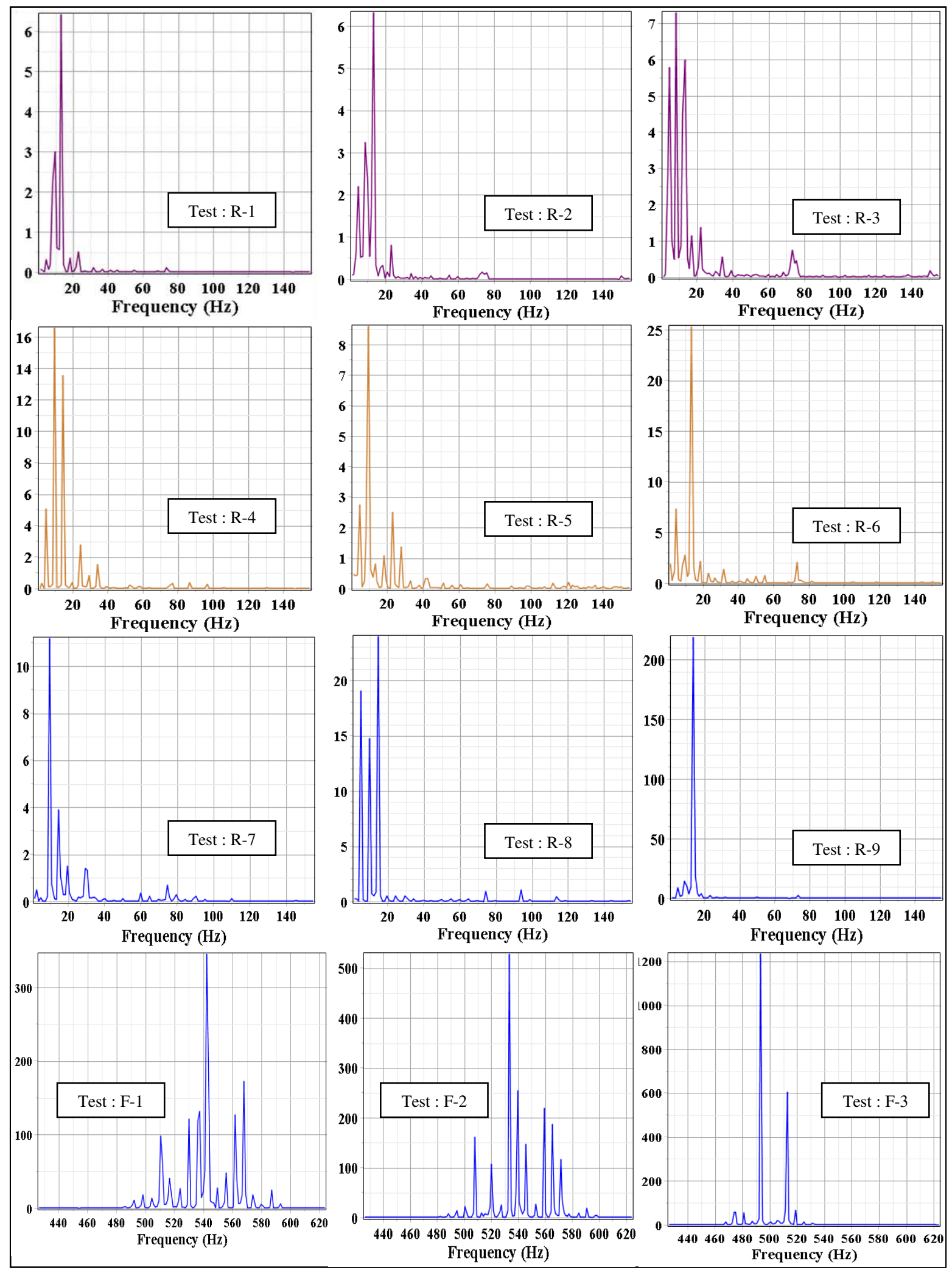

Figure 11.

FFT spectra of radial vibrations of the workpiece wall during experimental roughing and finishing operations. 


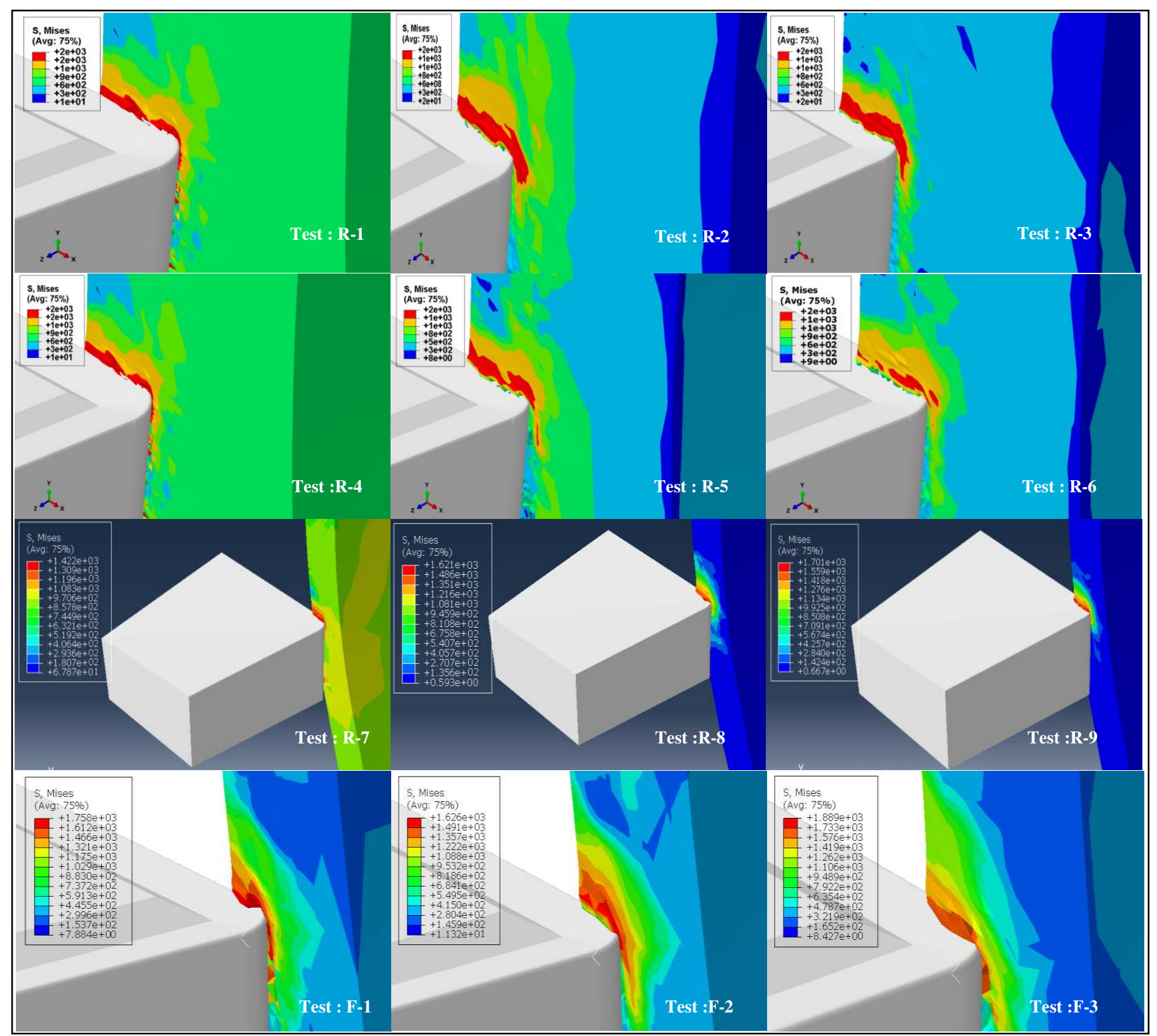

Figure 12. Simulated Von Mises equivalent stresses (MPa) for roughing and finishing

operations

\section{Conclusion}

This work gives focuses on the dynamic behavior of thin-walled workpieces made of 42CrMo4 steel alloyduring turning process. The impact of feed rate as well as the thickness of the wall part on the cutting forces and workpiece displacements has been investigated both experimentally and numerically 
during roughing and finishing operations. The proposed FEM, using Abaqus/Explicit software, is based on the behavior law of Johnson-Cook for the workpiece material. The detachment of the chip is simulated by a ductile fracture law of Johnson-Cook. The simulated cutting forces and the wall workpiece displacements are validated according to a series of experiments performed in the same cutting conditions. In the model, the cutting tool is considered to be a rigid body (to simplify the model and reduce calculation time) and animated with a forward movement at constant speed. However, the workpiece, animated with rotational movement, is considered as a deformable body, in order to most simulate its rotation and its dynamic behavior.

From this investigation, the following conclusions can be drawn.

1. Cutting forces and the quality of the machined surface depend not only on the choice of the feed rate but also on the dynamic behavior of thin-walled parts due to their low rigidity and low structural damping during of the machining operation.

2. The average values of the cutting forces and of the radial displacement of the workpiece wall are proportional to the feed rate. These average values are slightly influenced by the wall thickness of the machined parts.

3. The variation of the radial, tangential and axial components of the cutting force as well as the radial displacement of the workpiece wall around their average value is low for the roughing tests where the wall thickness is considered large. However, this variation intensifies for the finishing tests where the wall thickness is thin. These variations have a significant effect on the quality of the surface finish of the workpiece wall.

4. The stress distribution is concentrated in the cutting zone. It reaches its maximum value at the cutting edge contact of the tool and workpiece. Analysis of results allowed deducing the existence of shear zones at the edge of the tool throughout the cut.

5. The numerical model results can be improved by integrating the effect of temperature, tool wear and the variation of the specific cutting energy during the turning operation. 


\section{Declarations}

Funding: No funding was received to assist with the preparation of this manuscript.

Conflict of interest: The authors declare that they have no conflict of interest.

Availability of data and materials: The datasets generated and/or analyzed during the current study are available from the corresponding author on reasonable request.

Code availability: The code used in this study is available from the corresponding author on a reasonable request.

Author contribution: Zied Sahraoui: software, investigation, validation, methodology, writingoriginal draft. Nawel Glaa: supervision writing — software and reviewing. Kamel Mehdi: experimental tests, methodology, writing — reviewing and editing.

Ethical approval: Not applicable to this study.

Consent to participate: Not applicable to this study.

Consent to publish: Not applicable to this study.

\section{References}

1. Mabrouki T, et al. (2016) Some insights on the modelling of chip formation and its morphology during metal cutting operations. Comptes Rendus Mécanique, 344(4-5) :335-354. https://doi.org/10.1016/j.crme.2016.02.003

2. Monka PP, Monkova K, Majstorovic VD et al. (2020) Optimal cutting parameter specification of newly designed milling tools based on the frequency monitoring. Int $J$ Adv Manuf Technol. https://doi.org/10.1007/s00170-020-06169-x

3. Glaa N, Mehdi K, Zitoune R (2018) Numerical modeling and experimental analysis of thrust cutting force and torque in drilling process of titanium alloy Ti6A14V. Int J Adv Manuf Technol. 96(58):2815-2824. https://doi.org/10.1007/s00170-018-1758-7

4. Mejri H, Mehdi K (2019) Modeling of cutting forces in curvilinear peripheral milling process. Int J Adv Manuf Technol, 102(1-4):277-291 https://doi.org/10.1007/s00170-018-03249-x 
5. Li A, Zhao J, Luo H, et al. (2012) Progressive tool failure in high-speed dry milling of Ti-6Al-4V alloy with coated carbide tools. Int $J$ Adv Manuf Techno 58:465-478. https://doi.org/10.1007/s00170-011-3408-1

6. Ezugwu EO and Wang ZM (1997) Titanium alloys and their machinability. J. Mater. Process. Technol., https://doi.org/10.1016/S0924-0136(96)00030-1

7. Joshi S, Tewari A, Joshi SS (2015) Microstructural Characterization of Chip Segmentation Under Different Machining Environments in Orthogonal Machining of Ti6Al4V. J. Mater. Process. Technol. 137(1): 011005 (16 pages). https://doi.org/10.1115/1.4028841

8. Mabrouki T, et al. (2008) Numerical and experimental study of dry cutting for an aeronautic aluminum alloy (A2024-T351). International Journal of Machine Tools \& Manufacture, 48: https://doi.org/1187-1197.

9. Mabrouki T, Rigal JF (2006) A contribution to a qualitative understanding of thermomechanical effects during chip formation in hard turning. J. Mater. Process. Technol., 176:214-221. doi:10.1016/j.jmatprotec.2006.03.159

10. Xu Y, Wan Z, et al. (2020) Experimental study on cutting force in utrasoninc vibration-assisted turning of 304 austenitic stainless steel. Proc IMechE Part B: J Engineering Manufacture; https://doi.org/10.1177/0954405420957127

11. Mehdi K, Rigal JF, Play D (2002) Dynamic behavior of a thin wall cylindrical workpiece during the turning process Part I: Cutting Process Simulation. J. Manuf. Sci. Eng., 124(3):562-568.

12. Mehdi K, Rigal JF, Play D (2002) Dynamic behavior of a thin wall cylindrical workpiece during the turning process Part II: Experimental approach and validation. J. Manuf. Sci. Eng., 124(3):569-580.

13. Lorong P, Larue A, Perez Duarte A (2011) Dynamic Study of Thin Wall Part Turning. Advances Materials Research, 223:591-9.

14. Gerasimenko A, Guskov M, Duchemin J, Lorong P, Gouskov A (2015) Variable compliance-related aspects of chatter in turning thin-walled tubular parts. Procedia CIRP. 2015; 31:58-63.

15. Sahraoui Z, Mehdi K, Ben Jaber M (2021) Experimental Study of the Dynamic Behaviour of Thinwalled Tubular Workpieces in Turning Cutting Process. J. of Advanced Manufacturing Systems (JAMS), 20(1):75-93. http://doi.org/10.1142/S0219686721500049

16. Sahraoui Z, Mehdi K, Ben Jaber M (2020) Analytical and experimental stability analysis of AU4G1 thin-walled tubular workpieces in turning process. Proc IMechE Part B: J Engineering Manufacture; 234(6-7):1007-1018. https://doi.org/10.1177/0954405419896115 
17. Jaton NW (2002) Modeling Chip Formation in Orthogonal Metal Cutting Using Finite Element Analysis. MSc. Thesis, Faculty of Mississippi State University, August 2002.

18. Sunil Dutta, Suresh Kumar Reddy Narala 2021 Investigations on machining characteristics and chip morphology in turning Al-Mn (AM) alloy using finite element simulation. Proc IMechE Part E: J. Process Mechanical Engineering https://doi.org/10.1177/09544089211014027

19. Grzesik W, Bartoszuk M, Nieslony P (2005) Finite Element Modeling of Temperature Distribution in the Cutting Zone in Turning Processes with Differently Coated Tools. Journal of Materials Processing Technology, 164-165:1204-1211.

20. Glaa N, Mehdi K, Moussaoui K, Zitoune R (2020) Numerical and experimental study of the drilling of multi-stacks made of titanium alloy Ti6-Al4-V: interface and burr behavior. Int J Adv Manuf Technol 107:1153-1162 https://doi.org/10.1007/s00170-020-05116-0

21. Glaa N, Mehdi K (2019) Modeling thrust cutting force and torque in a vibratory drilling process of titanium alloy Ti6Al4V. Int. J. Mech. Eng. Rob. Res. 8(4):607-612. https://doi.org/10.18178/ijmerr.8.4.607-612

22. Duan CZ, Doul T, Cai YJ, Li YY (2009) Finite Element Simulation and Experiment of Chip Formation Process during High Speed machining of AISI 1045 Hardned Steel. Int. J. Recent Trends in Eng., 1(5): 46-50.

23. Abushawashi Y, Xiao X, Astakhov VP (2011) FEM simulation of metal cutting using a new approach to model chip formation. International Journal of Advances in Machining and Forming Operations, 3/2:71-92. 